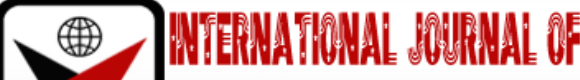

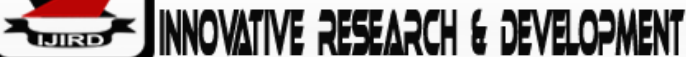

ISSN 2278 - 0211 (Online)

\section{Art-Teacher Education and the Realization of 2030 Education Agenda: Nexus for Sustainable Development in Nigeria}

Gandonu Sewanu Peter
Lecturer, Department of Fine and Applied Arts,
Dr. Kafaru Abiodun Babatunde
Adeniran Ogunsanya College of Education, Oto-Ijanikin, Lagos, Nigeria
Lecturer, Department of Fine and Applied Arts,
Adeniran Ogunsanya College of Education, Oto-Ijanikin, Lagos, Nigeria
Savage Olusegun Gabriel
Lecturer, Department of Art and Industrial Design,
Lagos State Polytechnic, Ikorodu, Lagos, Nigeria
SulukaAbedeen Babatunde
Lecturer, Department of Creative Arts,
Michael Otedola College of Primary Education, Epe, Lagos, Nigeria

\begin{abstract}
:
Art, being skill oriented may be perceived by many as mere self-exercise meant for a few talented ones; its strength in engendering skills for self- sustenance, practicality in eradication of poverty, and activation of economic sustainability and socio-political development of the society in general can be extraordinary; thus its inclusion in the school curriculum as a structured, formal subject. However, since the art teacher plays a prominent role in building desirable human capital required for this needed development in every society through impartation of functional education; it is important to redirect the art - teacher education programme itself towards developing skills that improve creativity, innovations, productive ability and entrepreneurial strength across all ages and genders to practicably align with the 2030 Education Agenda. This paper discusses the general overview of art, and art teacher education programme in Nigeria and the challenges involved in building human capacity concerning eradication of poverty in the country. It highlights the scope and benefits of the 2030 Education Agenda and suggests ways of redirecting art- teacher education in the track of realizing this universal agenda in order to actuate sustainable development in Nigeria.
\end{abstract}

Keywords: Art, art-teacher education, development, SDGs, MDGs, human capacity

\section{Introduction}

According to Sanubi \& Akpotu (2015), planning is a primeval aspect of human development. Aboluwodi \& Owolewa, (2018)also posit that preparing for the future has always been part of man; while World Economic Forum (2015) identifies collaboration, creativity and problem solving, character qualities like persistence, curiosity and initiative as skills and competencies needed to thrive in today's innovation-driven economy. These can be achieved through functional education; a well-structured, well-implemented and well-delivered art education programme. While a good art education programme will help in the attainment of these, the art teacher is the apex at the point of delivery.

Generally, while UNESCO (2019) charges thatevery child has the right to learn; it equally raises fears thatalthough more children are enrolled in school more than ever before, the teachers who are the apex duty-bearers obligated to realize this right for every child are collectively failing to improve learning. It reiterates that the failure is deep and broad, and has significant consequences. The report further expatiates that many children lack the knowledge and skills to realize their full potential and maximize their contribution to their communities; thus, the gap between the levels of learning that education systems are providing and what children, communities and economies need, is growing. It concludes that the breadth and depth of this learning crisis provides the greatest global challenge to preparing children and adolescents for life, work and active citizenship.

In many countries, inadequate training of teachers is holding back children's learning (Rose and Alcott 2015). What then is the status of art-education programme in Nigeria and what innovations can be made to help realize the 2030 Education Agenda in order to achieve sustainable development goals; especially reduction of poverty and hunger? What knowledge, skills, attitudes and values will today's (art) students need to thrive and shape their world? How also can art instructional systems develop these knowledge, skills, attitudes and values effectively? (OECD, 2018); these are critical issues that relate to art-teacher education; and the gap this paper sets to fill. 


\section{Conceptualization of Art}

The question of what art is, comes often and also generates many answers; many even disagree that it can be defined. Although, generally it can be considered in two ways: as a "process" or as a "product". As a process, art is the international organization of elements in a way that communicate to the senses or emotions; an endeavour which involves the translation of human thoughts and ideas into physical objects through application of skill to the use of materials and equipment. As a product, it can be considered as works produced through imagination and skill with attributes of beauty, but which expresses important ideas or feelings as in graphics, sculpture, painting, ceramics, and so on.

It is a practical phenomenon; a process and a product; where both the process (skill to do) and the product (created work) are marketable. Therefore, it was included in the school curriculum in order to afford every child the opportunity of learning well -structured art skills and practices in the formal school setting. This is as a result of its observed influence in human capacity development through acquisition and marketing of creative skills and products for self-sustenance in the quest for national development and sustainability.

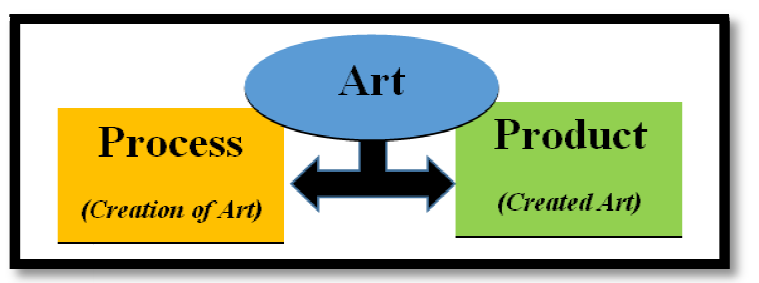

Figure 1: Art as Product and a Process

Source: Author (2020)

Relevant experiences and activities of art have been packaged into learnable contents and structured as a curriculum. This is offered in school to involve both theoretical and practical learning aspects; and taught and referred to as any of Fine art, Fine and Applied art, Visual art or Cultural and Creative arts; and offered at different levels of education world over, with the essence of improving creativity for productivity, entrepreneurship, poverty eradication and national development.

Alasa (2013) states that generally, an art curriculum should reflect a system approach to instruction with the recipients combining the knowledge of materials, tools, equipment (media), people, facilities, environment and imaginative reasoning to create objects of utilitarian or functional and aesthetic values for self-reliance and employment generation. However, in order to advocate and justify functional arts education for all, in a way that aids sustainability of individual and societal economy; there is need to align it with the dictates of modern developmental agendas. Thus, it is important to articulate the distinctive nature of art- teacher education and understand how it could deliver relevant instruction that uses arts to engage, affect and transform human lives positively (Antilla, 2018). With this in mind, the artteacher programme must therefore be better packaged to meet with societal needs. It is thus important to discuss the objectives of art-teacher education in Nigeria, its status and how it can be improved to align with the 2030 education agenda which is intended to positively affect all spheres of life through education. This equally includes art learning and art-teacher education; which are being discussed in this study in order to open a discourse that stimulate reasonable means of attaining Vision 2030 for sustainable development through the arts.

\section{Overview of Art-Teacher Education in Nigeria}

Teacher education refers to programme, training, policy and procedures to prepare prospective teachers with required skills, knowledge to undertake teaching related activities in their respective educational institutions. Art-teacher education thus refers to the entire process of training the art teachers to acquire relevant artistic skills as well as the methodology targeted at imparting skills in art, art appreciation and applications to the learners. It is important to note that quality is at the centre and there are dedicated targets on equity, qualified teachers, as well as safe learning environments (Garg, 2016). In this regard, the extent to which art teacher education in Nigeria has been able to attain these targets is of concern.

In Nigeria, art-teacher education is handled at the Colleges of Education and Universities with different curriculum. Objectives and overview of art teacher programme in Nigeria are as follows;

- To train young professional art teachers to fill the manpower needs of the primary and secondary schools;

- To equip and provide the teachers with knowledge, understanding and skills in Fine and Applied Arts;

- To equip students with the necessary knowledge and skills for the promotion of Nigerian and World's artistic and cultural heritage;

- To developing in the would-be teachers, the ability to communicate effectively through the arts;

- To prepare teachers to qualify for and benefit from teacher education at the university level; and,

- To equip Nigeria Certificate of Education graduates with manipulative skills which will make them self-reliant, job creators (National Commission for Colleges of Education, 2012).

\subsection{University Art-Teacher Education Programme in Nigeria}

The University is the highest institution of learning with the curriculum designed accordingly. Bachelor of Art (Education), Bachelor of Arts, Master of Art (Education), Master of Arts and Doctor of philosophy in Art or Art Education are different qualifying certificates awarded at the end of University art-teacher education programmes. The University 
system produces teachers for higher educational levels. However, the differences in degrees, depth of academic and artistic activities, as well as emphases in studio practice, art theory and teaching methodology are key areas of the university art teacher curriculum, including micro teaching and teaching practice.

Looking at the programme, the curriculum is designed to prepare prospective teachers to create, analyze, and appraise art pedagogy to fashion out how students can benefit from visual art knowledge in a complex economy. Chatham University (2016) clarifies that at this level, art teachers are trained to empower students through the integration of technical applications. Its further stresses that it will provides them with critical thinking skills that inspire marketable skills that lead to creative, scholarly, and leadership roles in the visual arts field. It concludes that it will also help to promote an understanding of the role that the visual arts play in all facets of contemporary life. The university art education programme achieves this through school- industrial linkages in form of Students' Industrial Work Experience Scheme (SIWES), Micro-teaching and Teaching Practice activities.

\subsection{College of Education Art-Teacher Education Programme}

The College of Education is an institution of higher learning, lower than the University, where teachers are trained to impart learning in the Basic and Post Basic Schools (Primary School up to Junior Secondary School). Art curriculum for this level is basically a 'train the trainers' programme where the core of it is the methodology of impartation of art learning. The certificate awarded here is the Nigeria Certificate in Education (NCE) which the teachers in training can also use for admission into the University or secure a teaching job in the basic schools.

Saibu (2013) states that generally, an art curriculum should reflect a system approach to instruction with the recipients combining the knowledge of materials, tools, equipment (media), people, facilities, environment and imaginative reasoning to create objects of utilitarian or functional and aesthetic values for self-reliance and employment generation.

\section{The 2030 Education Agenda}

Vision 2030 is a general agenda for the future; an attainable scheme, which articulates important lasting goals and prospects that will in the long run build and reflect the strengths and capabilities of countries of the world. According to UNESCO (2014), a strategic plan referred to as the Master plan for Visual Arts Development towards Vision 2030 is vigorously being followed by countries; the main features include: the formulation of a system of solutions throughout the value chain of artistic activities from creation, production, distribution and enjoyment of artworks; building and enhancing the system of legal documents on arts with a view to motivating artists' creativity, honouring artisans and applied art designers; improving expertise, management, research, and sales of works of art as well as renovating art training curricula in many universities and colleges so as to approach the regional and international levels, and having appropriate remuneration for talented artists and sculptors; It also includes investing in facilities and strengthening the socialization in the creation and production of art works; intensifying research and applying scientific and technological advances in the creation, production, distribution and consumption of art products.

Kingdom of Cambodia Nation Religion King (2014) emphasizes the need to ensure that academic staff and students, especially postgraduates, contribute to improving the research and development culture to serve national development needs; encourage aSll faculty members to develop research and consultancy services that strengthen and benefit countries' culture, identified national skills needs and development priorities; develop a comprehensive staff professional and career development scheme that encourages excellence in learning, teaching, research, and management. The United Nations set the Millennium Development Goals to tackle the problems of poverty, hunger and other social problems especially in the developing countries; it was assumed that by 2015 most countries in the developing world would have minimized the effects of famine, drought, poverty, hunger, HIV/AIDS and others in their environments, many countries managed to achieve marginal results in reducing the effects of famine, drought, poverty, hunger, and HIV/AIDS; thus, the need to consolidate on these marginal results must have informed the creation of Sustainable Development Goals (SDG)s with 17 items and a focus on the eradication of poverty and hunger by 2030 (Aboluwodi \& Owolewa, 2018).

Education is central to the realization of the 2030 Agenda for Sustainable Development. Education within the comprehensive 2030 Agenda is essentially articulated as a stand-alone Sustainable Development Goal (SDG 4) which aims at ensuring inclusive and equitable quality education and lifelong learning opportunities for all. It is a global commitment to ensure equitable opportunities to education in a holistic and lifelong learning perspective based on a humanistic approach in which education is seen as a fundamental right and a public good (Tawil, 2016).

Hinzen \& Schmitt (2016) enumerate the SDGs Goal 4: According to them, Quality Education Targets for achieving Vision 2030 Education Agenda include benchmarks that by 2030; countries should:

- Ensure that all girls and boys complete free, equitable and quality primary and secondary education leading to relevant and effective learning outcomes,

- Ensure that all girls and boys have access to quality early childhood development, care and pre-primary education so that they are ready for primary education,

- Ensure equal access for all women and men to affordable and quality technical, vocational and tertiary education, including university,

- Substantially increase the number of youth and adults who have relevant skills, including technical and vocational skills, for employment, decent jobs and entrepreneurship,

- Eliminates gender disparities in education and ensure equal access to all levels of education and vocational training for the vulnerable, including persons with disabilities, indigenous peoples and children in vulnerable situations, 
- Ensure that all youth and a substantial proportion of adults, both men and women, achieve literacy and numeracy,

- Ensure that all learners acquire the knowledge and skills needed to promote sustainable development, including, among others, through education for sustainable development and sustainable lifestyles, human rights, gender equality, promotion of a culture of peace and non-violence, global citizenship and appreciation of cultural diversity and of culture's contribution to sustainable development.

Hinzen \& Schmitt(2016 ) refers to Sustainable Development Goals (SDGs) as the new global architecture of the international community up to the year 2030. They were agreed upon by the United Nations in September 2015, following the Millennium Development Goals (MDGs) which resulted from the UN Summit in the year 2000; whereas the 8 MDGs were predominantly focusing on the so-called developing countries, the 17 SDGs have a clear global commitment for all nations and their people.

\section{Aligning Art-Teacher Education in Nigeria with Vision 2030 Education Agenda}

UNESCO (2014) alerts that there is need to improve the national system of training centres, complete the technical infrastructure, prioritize the development of human resources, pupils, students, creative individuals such as artists, sculptors, teaching staff and researchers, critics and curators, management staff of visual arts and so on; develop arts, motivate the creation of applied art designs and products to satisfy the demand of consumption and export.

Teachers play a key role in the appropriate socialization of young people for sustainable development as being targeted by vision 2030 directive; it is therefore important that, irrespective of the academic subject matter for which a primary or secondary school teacher is responsible, the teacher's major overall responsibility be seen as the moulding of socially and emotionally well-adjusted individuals. The teacher needs to assist the young students to feel good about themselves; to be emotionally secure and self-confident, to respect themselves and others, and to take full responsibility for their actions. (UNESCO 2008)

Similarly, OECD (2018) stresses that education has a vital role to play in developing the knowledge, skills, attitudes and values that enable people to contribute to and benefit from an inclusive and sustainable future. It illuminates that learning to form clear and purposeful goals, work with others with different perspectives, find untapped opportunities and identify multiple solutions to big problems will be essential in the coming years. Thus according to the report, education needs to aim to do more than prepare young people for the world of work; it needs to equip students with the skills they need to become active, responsible and engaged citizens.

Walling \& Davis (2020) also emphasize that national efforts must be focused on improving the quality of teacher education in the arts, and emphasize a comprehensive approach to teaching and learning in and through the arts; among which include: relationships and responsibilities of the art educator, the professional artist, and the professional general educator in teaching and teacher preparation in the visual arts; appropriate entry levels into practice for the art educator; and validation of the basic preparation for teachers. According to them, both the National Art Education Association (NAEA) and the Council of Chief State School Officers (CCSSO) have initiated efforts to establish performance-based standards for the preparation of specialist and classroom teachers in the arts. The NAEA standards deal with the visual arts specialist teacher only, while the INTASC standards deal with all of the arts, for the elementary arts specialist teacher and the classroom teacher.

Both efforts herald a new direction for art-teacher education, in that both are based on performance standards for the prospective teacher as opposed to programme standards that are often based on increments of time. This relates to the issue of competency of the would-be art-teacher. However, OECD (2018) emphasizes that the concept of competency implies more than just the acquisition of knowledge and skills; it involves the mobilization of knowledge, skills, attitudes and values to meet complex demands. According to the report, future-ready students will need both broad and specialized knowledge. Since this is so, the teachers must be trained in this direction.

Art is a way of life and cannot be separated from culture and how the people are living. UNESCO (2008) corroborates that our personal paradigms, our belief systems which we seldom subject to question, play a dominant role in determining how we experience life. It is therefore very useful to examine our paradigms to determine whether or not they are serving in our best interests, and whether we need to change them, because often when we change our personal paradigms, our experience of reality changes

Another one is to ensure that all art education graduates are equipped with knowledge and skills that allow them to contribute fully to national development in a rapidly changing environment. Also, it is important to make sure that all programs are developed in conjunction with analysis of national training provision and skill needs; while planning, financing, monitoring, review and reporting systems in higher education is achieved by development of a plan to improve governance and management in the higher education sector. (Kingdom of Cambodia Nation Religion King, 2014).

\section{Implication for Art Education and Sustainable Development in Nigeria}

Sustainable development is the idea that human societies must live and meet their needs without compromising the ability of future generations to meet their own needs (Youmatter, 2020). United Nations observe that each country faces specific challenges in its pursuit of sustainable development; and that billions of citizens in countries continue to live in poverty and are denied a life of dignity. It clarifies that the most vulnerable countries and in particular, African countries deserve special attention. This attention will be fine if it goes in the direction of education for empowerment, self-reliance and poverty eradication, which art education can offer if there are qualified teachers to teach a curriculum aligned to the attainment of vision 2030 education agenda.

UNESCO(2016) expects that upon completion of the full cycle of primary and secondary education, all children should have established the building blocks of basic literacy and numeracy skills and achieved an array of relevant 
learning outcomes as designed by and measured against established curricula and social standards, including subject knowledge and cognitive, non-cognitive and artistic skills that enable children to develop to their full potential.

\section{Conclusion and Recommendations}

This study concludes that art-teacher education is important in ensuring sustainable development especially in the areas of skill acquisition for human capital development, self-sustainability and others. This is in line with UNESCO (2008), which posits that education must effectively empower all people to make responsible and informed decisions, both individually and collectively, thus preparing them to successfully deal with present and future challenges and to commit their active participation in the construction of common future for all.

- Critical thinking, analytical and leadership skills should be included in all art-teacher education programme or courses and curriculum

- They should be taught to impart in the students' practical and theoretical applications which relate to market needs for sustainability.

- Art-teacher education curriculum should be made to function effectively for the appropriate socialization of art learners, especially in the area of empowerment.

\section{References}

i. Aboluwodi, A., \& Owolewa, O. (2018, January). Repositioning Education to Achieve Sustainable Development Goals in Nigeria. International Journal of Advanced Research in Public Policy, Social Development and Enterprise Studies (IJARPPSDES), 3 (1), 2536-6556. http://www.internationalpolicybrief.org

ii. Alasa, S. (2013). Contemporary issues in Fine and Applied Arts Education in Nigeria and the Way Forward. International Journal of Science and Research, 2(6), 13-16. http://www.ijsr.net

iii. Antilla, E. (2018). Art Education Promotes the Development of the Child and the Society. In M. Matthes, L. Pulkkinen, C. Clouder, \& B. Hey (Eds.), Improving the Quality of Childhood in Europe (Vol. 7, pp. 61-72). Brussels: Alliance for Childhood European Network Foundation. http://www.allianceforchildhood.eu/publications

iv. Chatham University. (2016, October 23). Visual Arts Curriculum. Retrieved June 3rd, 2020, from Chatham University: http://www.chatham.edu

v. Garg, S. (2016, April Monday 18th and Tuesday 19th). Sustainable Development Goal 4. Thinking about Teachers, Teaching and the 2030 Agenda for Sustainable Development. Faculty of Education, Cambridge University.

vi. Hinzen, H., \& Schmitt, S. (2016). Advancing EFA and MDGs to Goal 4 in the Sustainable Development Goals: Will there be wider benefits for adult education and learning in sustainable development? In H. Hinzen, \& S. Schmitt (Eds.), Agenda 2030 - Education and Lifelong Learning in the Sustainable Development Goals (pp. 8-15). Bonn, Germany: DVV International.

vii. Kingdom of Cambodia Nation Religion King. (2014, April 01). Policy on Higher Education Vision 2030. Cambodia: Ministry of Education, Youth and Sport.

viii. National Commission for Colleges of Education; (2012). Nigeria Certificate in Education Minimum Standards for Vocational and Technical Education. Abuja: National Commission for Colleges of Education.

ix. OECD. (2018). The future of education and skills Education 2030. Paris, France: Directorate for Education and Skills-OECD. http://www.oe.cd/education2030

x. OECD. (2018, 5th April). The future of Education and Skills - Education 2030.E 2030 Position Paper. http://www.oecd.org

xi. Rose, P., \& Alcott, B. (2015, September 22). Five steps to Achieving the goals of educating every child in the world. The Guardian.http://www.theguardian,com/amp/s/am

xii. Sanubi, F., \& Akpotu, N. (2015, March). The Nigeria Education System and Vision 20: 2020: A Crirical Development Planning Perspective. International Journal of Educational Administration and Policy Studies, 7(2), 26-38. doi:10.5897/IJEAPS2014.0371

xiii. Tawil, S. (2016). Education and the 2030 Agenda for Sustainable Development. In H. Hinzen, \& S. Schmitt (Eds.), Agenda 2030 - Education and Lifelong Learning in the Sustainable Development Goals (pp. 16-24). Bonn, Germany: DVV International.

xiv. UNESCO. (2008). Teachers' Guide for Education for Sustainable Development in the Caribbean. Santiago- Chile: UNESCO Regional Bureau of Education for Latin America and the Caribbean OREALC/UNESCO. https://unesdoc.unesco.org

xv. UNESCO. (2014, July 25). Master plan for visual arts development towards 2020, vision 2030. http://www.unesco.org

xvi. UNESCO. (2016). Incheon framework for action implementation of sdg 4.Education 2030: www.uis.unesco.org

xvii. UNESCO. (2019). Every Child Learns- UNESCO Education Strategy 2019 - 2030. New York: UNICEF.

xviii. United Nations. (n.d.). Transforming our world: The 2030 agenda for sustainable development. United Nations. http://www.sustainabledevelopment.un.org

xix. Walling, D., \& Davis, J. (2020). Art Education: School, Preparation of Teachers. Art Education: https://www.stateuniversity.com

xx. Youmatter. (2020, May 26th). Sustainable Development- What is it? Definition, History, Evolution, Importance and Examples. Youmatter. http://www. youmatterworld.com 